\title{
What Is a Good Tomato? A Case of Valuing in Practice
}

\author{
Frank Heuts and Annemarie Mol
}

\begin{abstract}
As a contribution to the field of valuation studies this article lays out a number of lessons that follow from an exploratory inquiry into 'good tomatoes'. We held interviews with tomato experts (developers, growers, sellers, processors, professional cooks and so-called consumers) in the Netherlands and analysed the transcriptions carefully. Grouping our informants' concerns with tomatoes into clusters, we differentiate between five registers of valuing. These have to do with money, handling, historical time, what it is to be natural, and sensual appeal. There are tensions between and within these registers, that lead to clashes and compromises. Accordingly, valuing tomatoes does not fit into inclusive formal schemes. Neither is it simply a matter of making judgements. Our informants told us how they know whether a tomato is good, but also revealed what they do to make tomatoes good. Their valuing includes activities such as pruning tomato plants and preparing tomato dishes. But if such activities are meant to make tomatoes good, success is never guaranteed. This prompts us to import the notion of care. Care does not offer control, but involves sustained and respectful tinkering towards improvement. Which is not to say in the end the tomatoes our informants care for are good. In the end these tomatoes get eaten. And while eating performs tomatoes as 'good to eat', it also finishes them off. Valuing may lead on to destruction. An important lesson for valuation studies indeed.
\end{abstract}

Key words: valuation; valuing; practice; performativity; eating; food; care; tomatoes

Frank Heuts, Department of Sociology and Anthropology, University of Amsterdam, the Netherlands, f.heuts[at]gmail.com

Annemarie Mol, Department of Sociology and Anthropology, University of Amsterdam, the Netherlands, a.mol[at]uva.nl

(C) 2013 Frank Heuts and Annemarie Mol. Photo from iStockphoto.

LiU Electronic Press, DOI 10.3384/vs.2001-5992.1312125

http://valuationstudies.liu.se 


\section{Valuation Studies}

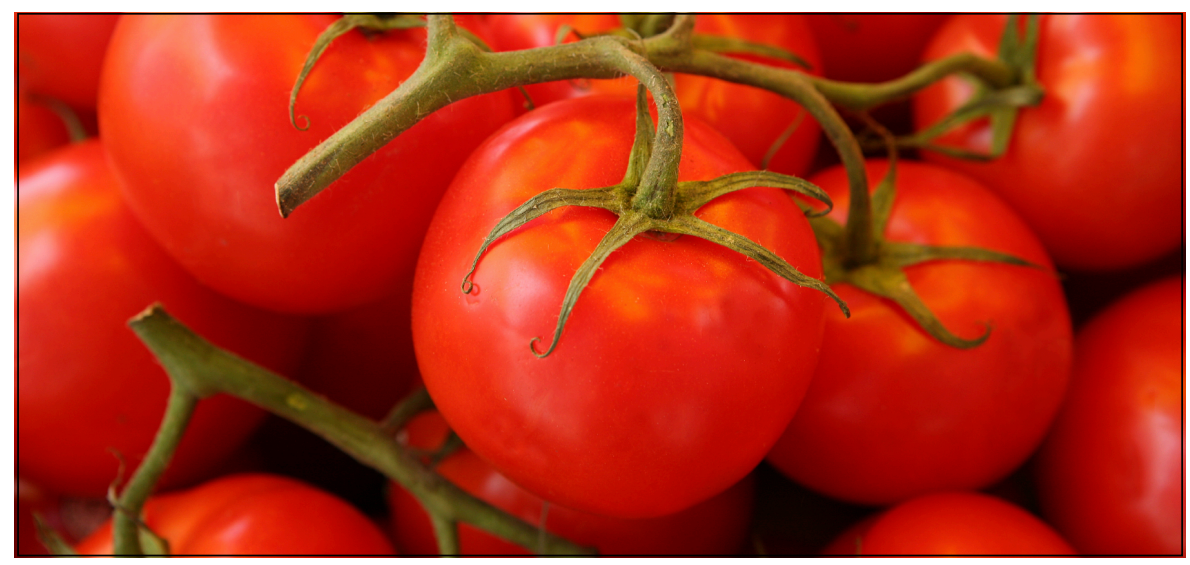

This article starts from the question: 'What is a good tomato?' However, it is not our aim to provide you with a conclusive answer to that question. It would have been possible to try. We might have gathered the views of a variety of experts and added these together to create an overall judgement. These are the four (or the twenty-seven) criteria that tomatoes should meet in order for them to deserve the predicate 'good'. If that is the kind of lesson you are looking for, this article will disappoint you. But this does not mean that we are out to critique the activity of valuing tomatoes and to uncover what hides behind it—be it financial interests, political power, or the desire to stand out and distinguish oneself. Instead, we are curious about valuing itself: what kind of activity is this? What emerges in practices where the 'goodness' of figures such as 'tomatoes' is at stake? In short, by exploring what 'good tomatoes' might be, we hope to contribute to the theoretical repertoire of the young interdisciplinary field of valuation studies, where concerns with 'values' that were earlier dispersed are being drawn together. ${ }^{1}$

Prominent among the topics addressed in valuation studies are the ways in which monetary value is established and tied up with qualifications of whatever it is that money can buy. ${ }^{2}$ But money and

\footnotetext{
${ }^{1}$ The possibilities for engaging in a social science focussed on objects, here tomatoes, owes a lot to studies of 'the social life of things' (Appadurai 1986). At the same time, it has been fuelled by the social studies of science and technology, where 'things' that form the object of science and/or intertwine with technology in other ways, are followed-and where, accordingly, 'the object' got centred and decentred at the same time (Law 2002). For the connection between things and moralities, see e.g. Myers 2002.

${ }^{2}$ It was actually only after we were exploring valuing for some time, that we realised that this particular term tends to be primarily used in the context of economic values (see e.g. Greaber 2002). We decided to hold on to this term when we found that 'valuation studies' is seeking to engage with a wide range of 'modes of valuing' (see Helgesson and Muniesa 2013). Our particular way of working is inspired by that of a variety of French pragmatists. See e.g. Thévenot 2001; Méadel and Rabeharisoa 2001; Hennion 2004; Latour 2005.
} 
markets are not the only contexts where valuing is a prominent activity. For instance, cultural sociologists are busy tackling how values are related to what they call taste; philosophers keep insisting on the relevance of normativity while separating this out into kinds; science and technology scholars wonder how the study of goods and bads in practice can best be added to the study of objects and subjects in practice; researchers of care analyse the pertinence of health, welfare and other goals locally cast as improvement; while in anthropological work embodied appreciations are being explored. ${ }^{3}$ Against the background of these varied literatures we sought to think through 'valuing' by engaging in an exploratory study of a telling case. For crafting a rich theoretical repertoire, or so we contend, does not work by laying out solid abstracting generalisations, but rather by adding together ever shifting cases and learning from their specificities. The case of 'good tomatoes' is neither exotic, nor politically hot. To us that was part of its attraction: mundane cases tend to offer a researcher the license to explore freely while despite, or maybe because of, their mundanity, they may generate surprising lessons.

As we wanted to explore what a 'good tomato' might be, we sought informants in the know. But who is an expert on 'good tomatoes'? In the Netherlands, where we did our research, there are many. The country is a hot spot for tomato breeding, growing, trading and processing, while tomatoes are also a popular ingredient of daily Dutch cuisine. With some effort, FH, who did the interviews, managed to talk with people from all these worlds: developers, growers, sellers, processors, professional cooks and so-called consumers (who talked about buying, preparing, as well as eating tomatoes). In total FH taped and fully transcribed thirteen interviews. ${ }^{4}$ That we call all interviewees 'experts' signals that we were not invested in differentiating between groups of people, those in the know, experts, and those without specialised insights, so called lay people. Instead, we wanted to explore different ways of valuing, relevant to different practices. We took our informants to be experts in relation to the practices that they were routinely involved in it, be it professionally or privately. An additional advantage of staging our informants as experts was that it allowed us, as researchers, to curiously analyse our materials without having to know better.

\footnotetext{
3 See, for our earlier struggles with the topic of taste Mol 2011; Mann et al. 2011; of philosophy Mol 2008b; of combining the study of ontology with that of normativity Mol 2012; and of appreciation Mol, forthcoming.

${ }^{4}$ All interviews were held in Dutch and literally transcribed (if not to the standards of conversation analysis as that was not needed for our purposes). For the sake of this English language article, we translate just the quotes we use. In this translation, even if we have tried hard to bring across the soul of what is said, subtleties, nuances and things that resonate in the choice of words, are inevitably lost.
} 


\section{Valuation Studies}

The aim of the interviews was to learn about valuing tomatoes in practice. Ideally, we would have wanted to do fieldwork and follow our informants in all their tomato related activities. This, however, wasn't easy to achieve in our practice. We had little time, wanted to know about diverse practices, and found that potential informants were not keen to be shadowed, either because this sounded intrusive to them, or because they did not want to negotiate it with their bosses. As our purposes were exploratory, interviewing proved a helpful enough proxy. We invited informants to talk as if they were their own ethnographers-or rather (as the object of conversation was not a tribe but a practice) their own praxiographers. ${ }^{5}$ Here the art is to persistently ask questions about the specificities of activities that informants tend to take for granted. This incites them to not get stuck in relating their opinions, but to take a fresh look at their own practices. Our informants were generous with their expertise and on average the interviews lasted for about an hour. Once we had the rich and heartfelt stories on printouts in front of us, it was tempting to write up the results in the form of 'tomato life worlds'. For that would have been a good humanist way to go, to describe 'worlds' with human beings in their centre. Different worlds, as the world of a tomato grower is not quite that of a tomato eater, while the trials and tribulations of sellers differ from those of seed developers. However, we had set out to study not groups of people, but practices of valuing. ${ }^{6}$ And as we kept foregrounding these, other ways to order our materials presented themselves.

A first one was to differentiate between various axes along which goods and bads get mapped. In making these axes we were, in a first instance, inspired by the differentiation that Boltanski and Thévenot made in the eighties between 'economies of worth'. ${ }^{7}$ This work moved

${ }^{5}$ For a more extensive introduction of this method, see Mol 2002.

6 If we would have laid out the 'worlds' as differing between social groups, as a symbolic interactionist would, we might have wondered about the way such worlds relate, clash and share 'the tomato' as a so called 'boundary object' (cf. Star and Griesemer 1989). This we do not do. However, like symbolic interactionism, we investigate valuing as something our informants do rather than in a more structuralist way as something caught in or framed by a 'culture'. See for inspiring examples of the latter the contributions to Watson and Caldwell 2005.

7 For the English translation, see Boltanski and Thévenot 2006. Their économies are inspired by the classics of Western philosophy as well as the rich and inspiring case studies of their research collaborators, that ranged from discussions in small town banks about giving or not giving out loans, to the question whether or not camembert remains authentic when it is safeguarded in a fridge. See Boltanski and Thévenot 1989. One of our reviewers wondered why we quote Boltanski and Thévenot since our approach has deviated so much from theirs. We hope that making the shifts explicit helps readers to better situate what we are after. There is obviously a lot of other work that is inspired by and then departs from the Boltanski and Thévenot line. See also Dodier 2012. 
from a philosophy invested in judgements and a sociology of critique, to the exploration of the ways in which ordinary people ('the actors') go about justifying their acts by evaluating them against one or more out of seven scales, called 'economies of worth'. As we did not explore the justification of acts (against the background of political philosophy), but the valuing of tomatoes (as a contribution to valuation studies), we allowed our theoretical tools to rapidly drift. Hence, we shifted from talking about 'worth' (a quality) to foregrounding 'valuing' (an activity) and from 'economies' (that come with a single gradient each) to 'registers' (that indicate a shared relevance, while what is or isn't good in relation to this relevance may differ from one situation to another). We drew the 'registers of valuing' that we came to disentangle from our materials, where they appeared neither closed off nor incompatible, but showed overlaps as well as internal tensions. As making ever more divisions in the hope of reaching purity proved to be futile, we took the complexity that ensued not as an analytical flaw, but as an empirical fact about the valuing of 'good tomatoes' ${ }^{8}$ That there are tensions within and between the registers of valuing tomatoes implies that as analysts we do not have to spend a lot of effort on taking a critical distance from our materials so as to avoid getting trapped in apparent self-evidences. As different registers of valuing clash, they rob each other of any potential self-evidence. They instantiate each other's criticism.

Valuing tomatoes is not just complex; it is also performative. Recently Vatin has argued that valuation studies should not just study evaluation, the activity of classifying things as either valuable or not, but also valorising, the activity of making things (more) valuable. ${ }^{9}$ Our materials back this up. As we asked our informants about 'good tomatoes' they did not just tell stories about how one might know which tomato is better or worse, but they also related what one might $d o$ to make a tomato better rather than worse. But while Vatin, in conversation with economic theories, locates evaluation in the market and valorising in the production process, in the case of good tomatoes both activities (as we will show below) are relevant all the way

8 For the argument that social science research should not hide the complexity of even messiness of the world, but find ways of bringing it out, see Law 2004.

9 See Vatin 2013. Vatin relates his argument to the possibilities offered by the French language where évaluer and valoriser are more obviously different while in the English valuation these activities seem to merge; but also to the relation between economics and the sociology of economy invested in studying market relations and the sociology of work invested in studying work. In the domain of food studies there are related separations, but there attending to production implies including agriculture, while studies of consumption are not so much invested in price as in 'food cultures'. In that context the argument that the production and the consumption best be analysed together has been variously made for quite a while, see e.g. Whatmore 2002 . 


\section{Valuation Studies}

through. Stronger still, they are hard to separate out. The 'assessment' part and the 'improvement' part of dealing with tomatoes slide over into each other. Hence, we do not follow Vatin in his suggestion to use two different terms for these activities, evaluation and valorising. Instead we stick to a single one: valuing. This gerund seems best suited for exploring varied ways of performing 'good tomatoes', from assessing and appreciating, to adapting and improving. 'Valuing' also stresses that 'valuation' is active, but beware, liberal notions of 'action' do not fit. For one, our informants do not act alone but in conjunction with lots of materials (from water to bumble bees to trucks to vinegar). And second, however much these clustered socio-material figures seek to make tomatoes good, success is never guaranteed. Which is why we come to mobilise the term care. Caring is an activity in which valuing is implied-both caring about and caring for have a 'good' at their horizon. At the same time caring indicates efforts that are ongoing, adaptive, tinkering and open ended. But before we give all our conclusions away, let us look at the case of good tomatoes.

\section{Registers of Valuing}

A first register relevant to valuing tomatoes is a monetary register, that has to do with financial costs. Most of the tomatoes that our informants talked about figure in market transactions, in which tomatoes move in one direction and money in the other. But money is even relevant to the amateur grower who neither sells nor buys his tomatoes: "It is a hobby. What with the plot, the seeds, the fertilizer and all, I doubt whether, as it is, I pay less than we would if we bought our tomatoes on the market. And then I don't even count my time." Stressing that in one's own particular case money is not a decisive value still evokes its relevance. And relevant it is, money. It informs ever so many dealings with tomatoes. A grower: "You want to discharge a minimal amount of fertilizer, for fertilizer costs money and you do not want to flush that into your waste water. Sometimes you see a number going up, like sodium. Then you have to act on it." But sometimes your own actions do not count for much. A grower: "Poland was too wet this year, Spain and Italy had a cold spring. That, when it comes to it, is what we thrive on." The fact that tomato markets extend across considerable geographical distances means that growers in the Netherlands earn more when the weather is bad in Poland, Spain and Italy. It also means that industrial processors will buy their tomatoes wherever the price is low. Here is one of them: "The Dutch ones, in boxes or in small containers, you pay two euros for those in the supermarket. Which means that when they leave the farm they are roughly one euro a kilo. For us that is way too much. We buy tomatoes grown in large fields, harvested with machines. And those are, what, some ten cents a kilo." Large Mediterranean fields, with no need for heating, yield cheap tomatoes. At the buying end of a 
transaction this is a good thing, cheap. Here is a consumer: "When there is a discount. I buy tomatoes when there is a discount." Thus, within the money register the good is not equivocal. 'Cheap' and 'expensive' are clashing goods. However, they both underscore the relevance of money.

A second register of valuing tomatoes has to do with handling them. One of the crucial concerns here is that of fragility. Fresh tomatoes are easily crushed and after a certain time, they perish. The spreadsheets of the market have no space for material specificities, nor for the passing of time, but when it comes to handling tomatoes, both are crucial. An industrial processor: "So they are harvested and then they go to the factory in big trucks. Ideally within eight hours. But, even if you are in a hurry, you should not pile up a tomato too high. Imagine what happens. If it is too high, your pile collapses." Here, a good tomato is firm, able to withstand transportation, if only its limits are respected. But even firm tomatoes go off in the end. Here the factory comes in. In factories tomatoes are processed and thus preserved. By cooking them up to a paste or a sauce, by tinning or bottling them, tomatoes that might otherwise quickly rot, are kept for future use. When it comes to handling fresh tomatoes, meanwhile, it is not just their firmness that matters. In kitchen practices other qualities are relevant as well. A cook: "A juicy tomato-that's nice. For a salad you want a juicy tomato. But not on bread, you don't, for bread easily gets soaked." Developers have taken this up as a challenge: how to avoid soaked bread and yet consume tomatoes? As one of them explains: "We have developed a tomato that is suited to being cut, the Intense tomato. This is a niche product. It is meant to be used in the sandwich industry, in catering. The Intense tomato won't lose its juice when you cut it." Thus, within this register the good again comes in varieties. But they all have to do with what makes a tomato good to handle.

In a third register, valuing proceeds by inserting tomatoes in historical time. Here it may be the past that is celebrated. A consumer: "When I was a kid. The way tomatoes tasted back then! Those were real tomatoes." In some places, notably in North America, heirloom tomatoes, so called 'old races', are being glorified. The literature offers plenty of quotes that signal this nostalgia: "Heirlooms are like motherhood and apple pie. You can't say anything bad about them. They're a status symbol."10 However, such reverence for the past

10 This is a quote of the famous US tomato expert Kanti Rawal and we found it in a book that is not about the good, but about the perfect tomato. See Allen 2010, 69. What we particularly like about this quote is that, by speaking about a 'status symbol', it is the developer who picks up on and mobilises a critical sociological repertoire. But mind you, he mobilises it to be critical, too, and in his own way: they may provide status, heirlooms, but there is still something left to develop and improve. 


\section{Valuation Studies}

seems to be rare among tomato experts in the Netherlands. While some older eaters glorify the tomatoes of their youth, our materials contain more instances where people take pride in breaking with the past, in being innovative. ${ }^{11}$ In this context the relevant 'past' is a fairly recent one, the nineteen eighties and early nineties, a time in which, as one of the growers put it, "we did not sufficiently attend to quality". Famously, at some point during that period, the Germans had started to complain that the Dutch tomatoes that they imported were shiny and firm, but tasteless. A grower: "As the Germans started to call them 'water bombs', we felt we had to act. So with some colleagues we decided to do things differently. We talked to seed developers, we stopped using pesticides, we fine-tuned nutrients. We branded them, too, we called them Tasty Tom. They are more expensive, our Tasty Tom, but we found a market for them." Such innovative zeal is more widely celebrated. Another grower: "Don't think of farms as stagnant, horticulture is developing really fast. We have this ultramodern packaging machine. And now we are building a climate controlled glasshouse." The innovative experiments may include the re-use of elements from the tradition. The first grower again: "We use bumblebees for fertilisation, and then we had to cut the pesticides because they make the bumblebees die off too quickly. So now we experiment with natural ways to discourage bugs." But in one way or another in this register good tomatoes are put on a time line. The present is differentiated from the past. A consumer: "For me, at first, well, tomatoes were just that, tomatoes. I actually used quite a lot of them, without thinking much about it. But since a few years now, I buy these smaller ones, on bunches, in a small plastic tray. Tasty Tom. They have a lot more taste. I go for those, now, I try to avoid the bigger ones." 12

A fourth register of valuing mobilised by the experts whom we interviewed is that of naturalness. Here things are good if they have not been interfered with. Even (or maybe especially?) the expert who works in the huge ketchup and sauce company that thrives on processing tomatoes, mobilises this register. He hands us an advertisement leaflet in which the company proudly underscores the 'goodness' of its wares with the slogan 'Grown, not made'. A short publicity film that shows how the tomatoes that go into Heinz ketchup

11 Now that we think of it, many people in the Netherlands wouldn't have much trouble with saying bad things about motherhood and/or apple pie either. To be explored! See also, for the triumphs and tribulations of writing in English about Dutch field work, and questions to do with valuing and language, Mol, forthcoming; and Kuipers 2006.

12 One may learn from Gomart and Hennion (1999) that the ability to discern which tomatoes have a good taste is not obvious but depends on training and dedication. Theirs was a breakthrough study into the activities required for 'passionate attachment'. See also Hennion 2001, 2007. 
are being grown has the same title. The suggestion is that what we see here is not an industrial but a biological endeavour. Tomatoes are not products; they are natural. It is quite an achievement of the Heinz marketing department that it manages to downplay the industrial activities necessary to grow and process tomatoes on a multinational scale. The informed bet is most likely that out there, in the public, the natural is widely celebrated. Some of our informants join in with that celebration. Here's a professional cook: "Look, if they [the growers] use pesticides and all, that bothers me. Then I won't buy there. I don't want them to interfere too much." But this is not to say that naturalness reigns supreme. Or even that, beyond advertisements, it may ever be achieved. A grower: "Organic tomatoes, well, of course that is a belief. Some aspects are good, they are good for the environment, they are rewarding on the market. But, you know, if consumers are being told, in the newspaper and all, that organic agriculture doesn't use any chemicals, what can I say? That is simply not true."

The fifth and final register of valuing that we draw out here is that of the sensual. Here, tomatoes are good if they are compelling to the senses. But which senses to seduce? First there are visual clues. A consumer: "Do they look good? Is their colour good, are they red? But also, do they have no mould, no weak and soft spots?" An attractive appearance may be pleasant in and of itself-for instance, used in a salad, a tomato should 'look good'. But appearance may also point to something else: a tomato with soft spots is on the verge of going off and a tomato with mould has already done so. Neither of these will taste good. Thus, visual signs may be used as an index of flavour and texture. But the signifying links are not always to be trusted. This was the problem with the 'waterbombs', they looked good, but they did not taste good. That visual signs may 'betray' those who look out for flavour is a contentious point, a crucial friction within the sensual register. A cook: "Some tomatoes have a tough skin. They may look good, but this is because they are hard, which is because they contain too much water. And then when you eat them, you get disappointed. They taste of nothing." So there may be tensions. Looks or taste. Smell or bite. The ideal is for a tomato to be appealing to all the senses at the same time. A developer: "Well, in the end, in one way or another, you want a tomato that is round, red, looks good and has a great taste."13

\footnotetext{
13 Anthropological studies on tasting often start out by saying that in 'the West' the eye is privileged among the senses, while 'elsewhere' smell or taste gets more attention (see e.g. Howes 1991). Others insist that in the way the body appreciates, the input from various sense organs flows over into each other; that humans are 'multisensorial'. What is striking in our tomato-materials, however, is how many different things people tell about the relation between what may be seen and what may be tasted. For a play on and with the senses-notably those of touch and tastesee Mann et al. 2011.
} 


\section{Valuation Studies}

\section{Relations}

These five registers do not simply jump from our materials. Instead, through careful analysis we have distilled them, like a chemist distils chemical components from a mixture. We used simple distillation techniques: if 'money' was mentioned in our materials a few times, we started using a colour pencil to colour all sentences with an allusions to money with a single colour. And if money was red, handling became blue, historical time pink, naturalness green and allusions to the senses yellow. ${ }^{14}$ This technique allowed us to first assemble sentences that mobilise just a single register of valuing. So far we presented you with such single-coloured ones. However, they formed only a small part of our materials. More often sentences ended up having a few colours as various registers were used in combination. This begged the question how the registers relate. Do they add together, are there situations in which tomatoes easily combine different kinds of goodness? This happens. But sometimes, different registers of valuing pull and push in different directions. Then one register may be prioritised over the others, or a compromise may be crafted. Compromises between different kinds of goodness, in their turn, come in variants. Here, rather than seeking to present you with a comprehensive overview, we will offer you an open-ended list of telling examples. ${ }^{15}$

The most striking tension between registers, mentioned time and again, is that between monetary and sensual valuing. A grower: "People may say they want quality but what are they willing to pay?" The implied answer is: not a lot. That this calls for compromise is something our informants mention in so many words. Another grower: "Taste is not counted by the kilo, but we are paid by the kilo. So you have to compromise and opt for a stock with a reasonable taste, that is still good when it comes to kilos." Consumers who buy and eat tomatoes also make compromises between money and taste. Then they buy something that is 'a bit expensive', but not 'excessively so', so as to eat something that may not be 'stunning' but is 'good enough'. But looking for the 'in between' is not the only way of seeking a compromise. It is also possible to shift from one register to another according to the circumstances. As a consumer puts it: "If I put a tomato in my pasta sauce, I tend to buy a cheap one, because it disappears into a pan anyway. But if, for instance, if I make a salad, then I buy a beautifully red one, preferably one that looks tasty. Then I

\footnotetext{
14 In a first round we used more colours, but those that appeared only rarely were later left aside. It also took us some time to decide to group 'the senses' together, rather than using either a term like 'quality' or splitting between looks and taste. For other purposes other ways of clustering might obviously make more sense.

15 For an inspiring exploration of the 'complexity' implied in another case, that of valuing a road planned in the Pyrenees, see Thévenot 2002a.
} 
really enjoy that, that its looks are so appealing." Here in one context, that of making sauce, money wins while in the other, making salad, sensual qualities count for most and tomatoes have to look tasty. But while the tension between costs and sensual qualities may be solved by a compromise (an in between) or distributed over situations (here this, there the other), sometimes one value overrules the other. Here is a consumer talking about the previously mentioned Tasty Tom: "Yes, I know them. I had them a few times when eating with a friend. They are very tasty. Really very tasty. But I never buy them myself. I think they are too expensive."16

Sensual qualities may also be in tension with ease of handling. A good example here is the use of fridges or cooling trucks. It is possible to protect tomatoes and transport them cooled down, in the hope that in this way they do not perish so quickly. A seller explains that 'in the old days', when tomatoes were hard and had a lower sugar content, this wasn't such a bad idea. But now it is. "You want to save them at a moderate temperature. Ideal is sixteen degrees. In a fridge tomatoes do not rot, but they go sour. The taste really deteriorates." One of the professional cooks we talked with is vehement about this. He buys his tomatoes directly from trusted organic growers, driving up from his city restaurant to their farms just to avoid all cooling. "I have a greengrocer who delivers right here, to my door. But he carries all his vegetables cooled. And for some products this is fine, but, let me tell you, a cooled tomato is a disgrace. If we have inspectors coming in, when they see a tomato that hasn't been cooled, they want to taste it. Why? Because they don't know any more what it is to eat uncooled tomatoes." However fierce this particular expert may be, many others have no inkling. A consumer tells that she saves her tomatoes in the fridge. Why? The very question surprises here. "Why I put them in the fridge? I guess because that's what my mother did. Is it bad?" When the interviewer reveals that saving tomatoes in a fridge might be bad for their taste, she looks astonished. In practice, then, the tension between cool ease of handling and warm care for tasting, hardly leads to compromises. Instead, in some places cooling is a matter of course. While elsewhere it gets rejected as a disgrace. ${ }^{17}$

\footnotetext{
16 As this kind of consumer is widespread, growers have so far not been able to establish an 'economy of qualities' (Callon, Méadel, and Rabeharisoa 2002) where a higher price is accepted for higher quality, in connection with suitable, shared techniques for recognising the relevant 'qualities'.

17 Interestingly, among the case studies that helped to inspire Boltanski and Thévenot, there is one that is about the question of the tension between quality and fridges as well. It regards camembert and the question whether this may still be called "traditional" when it is put in a fridge to last longer (Boisard and Letablier 1989).
} 


\section{Valuation Studies}

The sensual quality of tastiness may also either go together or clash with the good of being natural. In some places tomatoes from what is called 'mechanical production sites' are discarded because they lack both taste and naturalness. A high end cook: "Some tomatoes are mass produced, on a scale that is gigantic. Go to Malaga, you will find gigantic farms run by Dutch owners, tomato plantations. And they produce for [names of down-market supermarkets]. Very interesting if you want to see something mechanical. Bonkers. No taste whatsoever. Just inedible." But this is not to say that what gets positively valued in the register of naturalness and what comes out as good in a sensual register always go together. There may also be a clash. A grower: "The requirement for organic is: do not use potassium. But if you add potassium, tomatoes stay smaller. The sugar content goes up. Smaller tomatoes just taste better. For all kinds of reasons, organically grown veggies often taste great, but when it comes to tomatoes, they just do not. Ruling out potassium is a sad mistake." Thus, here we hit upon an irredeemable tension. A tomato that is 'natural' is not as 'tasty' as one that has been supplied with potassium, while a 'sweet' one, that is tasty thanks to the addition of potassium, is-under the current regulatory regime-not 'natural'.

\section{Care}

In the practices that our informants talk about, valuing is not a matter of casting judgements after the facts. Instead, it is part and parcel of a variety of activities that experts engage in to care for their tomatoes. ${ }^{18}$ We probed for this. At some point during his interviews $\mathrm{FH}$ would ask, 'If I would have to do your job [run your household] next week what should I do?'19 In this way we learned a lot about activities meant to achieve good tomatoes. For the qualities of tomatoes are not given, they may be tinkered with. A cook: "With a bad product, if you handle it with love, you may still improve that product." That qualities are not fixed characteristics of the object qualified does not imply that they depend on the eyes of the beholder. Instead they rather depend on the active contributions of the experts, be they developers, growers, processers, buyers, cooks or eaters. There is a lot to be done. Growing tomatoes is an obvious case in point: it involves all but

18 In this sense tomato experts resemble people involved in health care, who, likewise, are not primarily invested in judging, but rather seek to improve a situation -whatever 'improve' may locally mean-see e.g. Struhkamp, Mol, and Swierstra 2009. Shifting from bealth care to tomato care helps to strengthen an understanding of care as not so much a noun that designates a (social) domain, but rather a verb that signals an range of activities. See also Mol 2008a and the contributions to Mol, Moser, and Pols 2010. There is a resonance here as well with the notion 'matters of concern', see Latour 2004.

19 Telling others what they should/might do to acquire something that 'good', is also a rich textual genre-in case of growing, processing tomatoes, see e.g. Gould 1992. 
endless work. There is pruning. "The bunches, these we cut down to six tomatoes. If you do nothing you may get eight, nine, ten tomatoes. We prune all of them down to six, then you get good quality." There is watering. "We put the plant in a drain, forty centimetres above the ground. You may water to a schedule, or adapt to how much light there is, or use a balance for if a plant evaporates a lot it loses weight, so you may add water according to weight loss." There is the protection against parasites. "We have a biological way of countering bugs. As white flies deposit their eggs in the plant, we add ichneumon. These deposit their eggs in the eggs of the white flies, so that what comes out of such an egg is not a white fly, but an ichneumon." And so on, the list could easily be extended. ${ }^{20}$

As they work with their tomatoes our informants seek to make them good. Thus valuing does not just have to do with the question how to appreciate reality as it is, but also with the question what is appropriate to do to improve things. Take processing. In a register where naturalness is celebrated, cooking, condensing and conserving do not qualify as improvements, as they 'go against nature'. However, in a monetary register processing not only suits producers (who may earn a lot of money on this market) but also consumers (who tend to pay less for canned tomatoes than for similar amounts of fresh ones). In the register of handling, processing entails an improvement again as well, as it keeps tomatoes edible-still good to eat-long after the moment when, left to their own devices, they would have rotted. Processing may also make tomatoes easier to handle for a cook in an everyday kitchen, where opening a can and pouring the contents into a soup is a lot less work than peeling. Here is one of them: "To take the skin of a tomato, that's not my favourite chore. It's a nasty work, really. I only do it very rarely, you know. But, well, if I make a soup, this is a problem. For soup is simply not nice with wisps of skin in it. Argh. So then I peel. Or I cheat and use a can." The potential disadvantage, in the kitchen, of using a can, lies in the register of the senses. Soup from canned tomatoes may be less enticing than soup from freshly peeled ones. But it doesn't need to be. "When I make soup I use lots of fresh tomatoes. But then I add a can of tomato paste. There is so much taste in any single one of them!"

Valuing tomatoes, then, is embedded in activities that have other names-growing, cooking, eating, etc. And compromises between clashing values are not so much found (argumentatively) as well as

20 The list of the work involved would also get a lot longer if more experts would be interviewed, such as those who do the manual work (without also being in charge) on fields, in warehouses or in factories. That we have not included such informants is among the many limits of the present study; but see e.g. Barndt 2002. Another one is that we confined our investigations to conversations with informants in the Netherlands while tomatoes travel widely - and what they are or what is good or bad about them, varies along the way. See for this e.g. Rosset, Rice, and Watts 1999. 


\section{Valuation Studies}

crafted (materially). They depend on the practical possibilities of attuning one's work to different kinds of good at the same time. Take the industrial processor involved in making ketchup. It hopes for tomatoes that are easy to handle in the production phase (withstand mechanical harvesting and transport); and that lead on to a ketchup easy to handle at the dinner table (flowing out of the bottle neither too fast nor too slow). This ketchup also better be appealing to the senses (it should have the 'right' colour, texture and taste). If such a tomato does not yet exist, it has to be invented. This, then, is what the Heinz company has done-and it has patented the seeds. The relevant experts among our informants seem proud of it: "A tomato has to have a high viscosity. Therefore, if you squeeze in a Heinz tomato only a bit of juice will come out. It is very beefy, so that you can make a good, thick ketchup with it. It also has a high sugar content, for the sweeter the tomato itself, the less sweetener you have to add. And it has to be sturdy, too, for you have to be able to transport it." As tomatoes are not given, good tomatoes are not given either. And in the process of developing them, divergent qualities and requirements may be tinkered with in combination. ${ }^{21}$

What the case of tomatoes helps to bring out, is that such tinkering is not a matter of taking control. For tomatoes may be adaptable, but only within limits. What exactly their limits are, is not obvious from the start. It can only be experimentally discovered in the process of tinkering. You try pruning away a few branches and find that this increases the taste of the tomatoes on the branches that remain. You make soup without thinking to peel and find that you do not like the bits of skin in it. You want to present your tomatoes in an attractive way for the customers of the supermarket, but you have learned from experience that you better respect their fragility. A seller: "You have to present them in the box in which they arrive. You should never take a load of tomatoes out of one box and put them in another. Of course if there are just a few left, you may pile these on top of the next lot, in the next box. But you should not start handling a whole load of them, picking them up and putting them down, let alone pouring them from one box into another. Some people do, but it is bad for their quality." The fragility of tomatoes calls for the attentiveness of those who work with them. But however hard you try, working to improve tomatoes

21 While there is a lot of talk about healthy food these days, to our surprise our analysis did not bring out 'healthy' as a relevant register of valuing. At some point we wondered whether we had missed something. When searching for it, we found off handed remarks about tomatoes being healthy, 'of course'. Gradually it downed on us that if tomatoes are 'of course' healthy, this may become an uninteresting mode of valuing as there are no bad (unhealthy) tomatoes from which good (healthy) ones might differentiate. And as informants do not feel they have to do something to make tomatoes healthy. They just are. Some modes of preparation may be called more healthy than others-but among our informants that is the end of it. 
does not necessarily lead on to success. It is not a matter of taking control and imposing an ideal, but of caringly playing with possibilities, while staying attentive to what is good, not just about, but also for your tomatoes. A grower: "Well, yes, we try to make them happy! Water, light, nutrients, the lot of it. We give them what they want." If only you take proper care of your tomatoes, they care back. 22 This is not a symmetrical kind of care. Tomatoes owe their short lives to human beings, but then they get harvested, transported, sold, cooked up and eaten. Our informants, in their turn, owe (a part of) their income to tomatoes; or they thrive on them physically, as they enjoy, digest, absorb and metabolise tomatoes. ${ }^{23}$ And who in this relation has the most to give? Here's a cook: "When a tomato is good, you don't have to do much. Just a drop of balsamic. Or olive oil, pepper and salt. And then you are in heaven."

\section{Conclusion}

How good this is, being in heaven, might need a case study of its own. For now the question is what we have learned about valuing from the present case, that of good tomatoes. For while some scholars argue that the field of valuation studies should work towards a coherent theory, here we have taken another route. Throughout this text, while laying out the case of 'good tomatoes', we have carefully abstained from firmly defining our crucial terms and we have no ambition whatsoever to legislate how others should be using them. ${ }^{24}$ Opening up a research field, we contend, is not well served by fixing a collective language. This is not to say that cases should be studied in isolation from each other and encaged in their own corner. Instead, a good case study builds on and resonates with earlier ones while adding its own specificities to the collection. In this way each new case may help to expand and refine our collective abilities to recognise what may be the case in this or that site or situation. If as a research collective we abstain from fusing our different cases into a common scheme, but hold them in tension, each new case will better equip us to study valuing (valuation, evaluation, valorisation, etc.) in the next site or

22 Our analysis here is inspired by that of Harbers 2010, who mobilised a 'care' trope for analysing relations on the farm between farmers and animals-where farmers feed, water and otherwise care for the animals and the animals, by providing the farmers with a living, care back. In this, tomatoes, when it comes to it, are not so different. See also the wonderful chapter in Pollan 2002, where he analyses applegrowing from the perspective of the active apples.

23 Tomatoes cross bodily boundaries and come to be absorbed, see also Abrahamsson and Simpson 2011.

24 As to what the field should do, or might want to become, see the insightful overview of the members of the editorial and advisory boards of Valuation Studies (Kjellberg, Mallard et al. 2013). 


\section{Valuation Studies}

situation-while remaining open to what so far has not been noticed. For what is irrelevant in one site or situation, may be striking in another. And what has been remarked upon in one case is subsequently a lot easier to recognise once more. So what as a collective might we learn from the case of good tomatoes?

First, this case resists the simplification of a two or three dimensional scheme. Valuing tomatoes is hardly formalised and intersections and interferences abound. We brought out various registers of valuing, to do with money; handling; historical time; naturalness; and sensual appeal. But while each of these registers singles out a particular concern, what is good in relation to this concern varies between experts (sellers want to earn money, while buyers, by and large, do not like spending it ${ }^{25}$; and it varies between situations (while juicy tomatoes are good in a salad, firm ones are better for sandwiches). What is more, while the registers are a unity in one context (sensual qualities may jointly clash with monetary costs), elsewhere there are clashes within a register (for instance between the sensual qualities of looks and those of taste). Clashing 'goods' may side-line or overrule each other, or become fused into compromise (here price overrules taste; there taste overrules price; while elsewhere the search is for a middle way). Jointly these complexities imply that it is impossible to fit the case of 'good tomatoes' into a nice schematic overview. Time and again there are new shifts, contrasts and surprises. Hence, while above we argued against formulating an encompassing theory of valuing that seeks to be valid between and beyond cases, this particular case suggest that it may even be difficult or impossible to draw coherent conclusions about valuing in a single case, such as that of 'good tomatoes'. The lesson is that insights do not need to be schematised. Our informants, at least, never miss an inclusive formal scheme when in practice they value tomatoes.

Second, this case offers lessons about the performativity of valuing. So far, a lot of research into valuing has been informed by cases involving distant judgements. The justifications that Boltanski and Thévenot analysed took place before or after the act. The empirical studies in the fascinating book that accompanied their theoretical volume typically reported on meetings in which people deliberated about things being done outside the meeting room. ${ }^{26}$ A lot of

25 The 'by and large' is a caveat that indexes that this is not always the case. One of our colleagues writes in his comments on an earlier draft that when he wants to treat himself, he buys expensive tomatoes, looking forward to their great taste. But he suggests that maybe that moment of spending extra money gives him more pleasure than the actual taste.

26 Above we already mentioned the fabulous case of 'good camembert'. Another memorable one was done in a local bank and investigated on which grounds people might get, or not get, a bank loan. However, it was a result of sitting in meetings again. See Boltanski and Thévenot 1989. 
philosophical work on normativity implicitly reflects on the normative tasks of outsiders such as judges who qualify other people's actions while seated on an elevated platform in clothing that is visibly distinct. The favourite model of classic cultural sociology is the art critic who may either praise or discard a painting, but all the while keeps his hands on his backs. If he were to take out a black marker and add a few lines for additional contrast, the museum guards would intervene. In contrast, the experts whom we interviewed all have hands-on relations to their tomatoes. Their assessments and their improvements go together. In their practices valuing is not an exclusively judgemental, nor a separate activity, but mixes with developing, growing, processing, selling, cooking, cutting and eating. Hence, not just seed developers strive after 'good tomatoes', but so, too, do growers, processors, sellers (do not stock them too high!) cooks (do not keep them in the fridge! Add balsamico!) and even eaters (if only by actively attending). And as realising 'good tomatoes' is spread out, this case suggests that judging, improving, appreciating, and lots of other activities as well, may all be relevant for what it is to value.

Third, the activities meant to make tomatoes good do not offer control. Most of the mundane practices where tomatoes are being improved have not been tamed to fit standards. They are populated by all kinds of obdurate factors and actors (from soil, to trucks, to knives and everything in between) and whenever something happens, all of these respond in their own different ways. Sometimes they are predictable, but often they are not. Hence we called the work that our informants invest in achieving 'good tomatoes' care. The term 'care' suggests enduring work that seeks improvement but does not necessarily succeed. It also implies that the object of improvement should not be overpowered, but respected. Respect does not depend on leaving things and situations as they are. Instead it is a matter of calling on strengths and tinkering with weaknesses. The implication is that not just any goal can be set. Instead the values targeted, the objects being valued and valuing subjects come to gradually coconstitute each other. Hence, traits like viscosity and sugar content cannot all by themselves mark the 'value' of tomatoes. They intertwine with such things as the susceptibility of bumblebees to pesticides, the latest legislation about whether or not adding potassium is 'natural', or the vinegar at hand in one's kitchen. All these and many more materialities and practicalities inform and co-shape what valuing tomatoes comes to be in practice. Here is the lesson: valuing does not depend on fixed variables.

The fourth and final lesson of our case has to do with eating. So far we have left this in the shadow, but eating forms the soul of the case of 


\section{Valuation Studies}

good tomatoes. ${ }^{27}$ For a start, it is one of the many performative formats that valuing may take. For whether it is done attentively and in savouring mode, or hastily, out of routine or hunger, eating enacts the tomatoes being eaten as good to eat-rather than as inedible or waste. What is more, eating also forms the horizon of all the other tomato-activities in which our informants engage. It is, after all, because they are 'good to eat' that tomatoes are worth growing, transporting, buying, cooking or caring for in other ways. However many modes of valuing there are, and whatever the clashes and compromises between them, they would not occur if tomatoes were not also good to eat. But while the activity of eating crucially values tomatoes in a positive way, it also destroys them. After lunch the shiny red, juicy exemplar that looked so attractive in your salad, is no longer to be seen. Its taste may rapidly vanish or linger for some while, but one way or another your enjoyment doesn't last. You may digest and absorb the components of your tomato and these may be put to work inside your body allowing you to smile, walk or read an article, but there is no longer a distinguishable 'tomato' left. As eaters chew, swallow and digest tomatoes, they perform them as good, but also finish them off. Hence, in the case of tomatoes valuing does not only go together with caring (improving, adding worth), but also with destroying (killing, metabolising, decomposing). This is an important lesson that the specificities of our case bring home. Exploring 'good tomatoes' is not just a contribution to valuation studies, but also suggests that devaluation studies are equally relevant to do.

Acknowledgments. This text comes out of the research project 'Eating bodies in Western practice and theory' financed through an ERC Advanced Grant (AdG09 Nr. 249397-eatingbodies) gratefully acknowledged. One of the present authors, Annemarie Mol, leads this project. The other, Frank Heuts, took up the study of 'good tomatoes' as a case for his master's thesis in sociology under AM's supervision. We would like to thank the team, Filippo Bertoni, Sebastian Abrahamsson, Else Vogel, Michalis Kontopodis, Cristobal Bonelli and in this case (for their detailed comments) especially Anna Mann, Emily Yates-Doerr and Rebeca Ibanez Martin. For additional comments and encouragements we thank Olav Velthuis, Mieke Aerts, Rogier van Reekum, Thomas Franssen, Giselinde Kuipers, Tsjalling Swierstra, Mattijs van de Port, Bodil Just Christensen and John Law. Two anonymous reviewers and the editors of Valuation Studies were very helpful as well. And obviously we are most grateful to our anonymous informants.

27 'Eating' brings with it crucial shifts to various theoretical concerns. See for issues of relating, Bertoni 2013; for the issues to do with economic demand versus food need, Yates-Doerr 2012; and for subjectivity, Mol 2008b. 


\section{References}

Abrahamsson, Sebastian, and Paul Simpson. 2011. "The Limits of the Body: Boundaries, Capacities, Thresholds." Social \& Cultural Geography 12 (4): 331-338.

Allen, Arthur. 2010. Ripe: The Search for the Perfect Tomato. Berkeley: Counterpoint Press.

Appadurai, Arjun. 1986. The Social Life of Things: Commodities in Cultural Perspective. Cambridge: Cambridge University Press.

Barndt, Deborah. 2002. Tangled Routes: Women, Work, and Globalization on the Tomato Trail. Lanham, London: Rowman \& Littlefield.

Bertoni, Filippo. 2013. "Soil and Worm: On Eating as Relating." Science as Culture 22 (1): 61-85.

Boisard, Pierre, and Marie-Thérèse Letablier. 1989. "Un compromis d'innovation entre tradition et standardisation dans l'industrie laitière." In Justesse et justice dans la travail, edited by Luc Boltanski and Laurent Thévenot, 209-218. Paris: Presses Universitaires de France.

Boltanski, Luc, and Laurent Thévenot, eds. 1989. Justesse et justice dans le travail. Paris: Presses Universitaires de France.

. 2006. On Justification: Economies of Worth. Princeton: Princeton University Press.

Callon, Michel, Cécile Méadel, and Vololona Rabeharisoa. 2002. "The Economy of Qualities." Economy and Society 31: 194-217.

Dodier, Nicolas. 2012. "Ordre, force, pluralité. Articuler description et critique autour des questions médicales." In Faire des Sciences Sociales: Critiquer, edited by Pascale Haag and Cyril Lemieux, 317-342. Paris: Les Editions EHESS.

Gomart, Emile, and Antoine Hennion. 1999. "A Sociology of Attachment: Music Lovers, Drug Addicts." In Actor Network Theory and After, edited by John Law and John Hassard, 220-47. Oxford: Blackwell Publishers.

Gould, Wilbur. 1992. Tomato Production, Processing \& Technology. Timonium: CTI Publications

Greaber, David. 2002. Towards an Anthropological Theory of Value: The False Coin of Our Own Dreams. Palgrave McMillan.

Harbers, Hans. 2010. "Animal Love Stories: About Care and Economy." In Care in Practice: On Tinkering in Clinics, Homes and Farms, edited by Annemarie Mol, Ingunn Moser, and Jeannette Pols, 141-170. Bielefeld: Transcript Verlag.

Helgesson, Claes-Fredrik, and Fabian Muniesa 2013. "For What It's Worth: An Introduction to Valuation Studies." Valuation Studies 1 (1): 1-10.

Hennion, Antoine. 2001. "Music Lovers: Taste as Performance." Theory, Culture, Society 18 (5):1-22.

- 2004. "Pragmatics of Taste." In The Blackwell Companion to the Sociology of Culture, edited by Mark Jacobs and Nancy Weiss Hanradan, 131-144. Oxford/Malden: Blackwell. 


\section{Valuation Studies}

. 2007. "Those Things That Hold Us Together: Taste and Sociology." Cultural Sociology 1 (1): 97-114.

Howes, David. 1991. The Varieties of Sensory Experience: A Sourcebook in the Anthropology of the Senses. Toronto: University of Toronto Press.

Kjellberg, Hans, Alexandre Mallard, Diane-Laure Arjaliès, Patrik Aspers, Stefan Beljean, Alexandra Bidet, Alberto Corsín, Emmanuel Didier, Marion Fourcade, Susi Geiger, Klaus Hoeyer, Michèle Lamont, Donald MacKenzie, Bill Maurer, Jan Mouritsen, Ebba Sjögren, Kjell Tryggestad, François Vatin, and Steve Woolgar. 2013. "Valuation Studies? Our Collective Two Cents." Valuation Studies 1 (1): 11-30.

Kuipers, Giselinde. (2006) Good Humor, Bad Taste: A Sociology of the Joke. Berlin: Mouton de Gruyter.

Latour, Bruno. 2004. "Why Has Critique Run Out of Steam? From Matters of Fact to Matters of Concern." Critical Inquiry 30: 225-248.

- 2007. Reassembling the Social: An Introduction to Actor-NetworkTheory. Oxford University Press.

Law, John. 2002. Aircraft stories: Decentering the Object of Technoscience. Durham: Duke University Press.

- 2004. After Method: Mess in Social Science Research. Routledge.

Mann, Anna, Annemarie Mol, Priya Satalkar, Amalinda Savirani, Nasima Selim, Malini Sur, and Emily Yates-Doerr. 2011. "Mixing Methods, Tasting Fingers: Notes on an Ethnographic Experiment." HAU: Journal of Ethnographic Theory 1 (1): 221-243.

Méadel, Cécile, and Vololona Rabeharisoa. 2001. "Taste as a Form of Adjustment between Food and Consumers." In Technology and the Market: Demand, Users and Innovation, edited by Rod Coombs, Ken Green, Albert Richards, and Vivien Walsh, 234-253. Cheltenham: Edward Elgar Publishing.

Meyers, Fred, ed. 2002. The Empire of Things: Regimes of Value and Material Culture. Santa Fe: School of American Research Press.

Mol, Annemarie. 2008a. The Logic of Care: Health and the Problem of Patient Choice. London: Routledge.

- 2008b. "I Eat an Apple: On Theorizing Subjectivities." Subjectivitiy 22: $28-37$.

—. 2011. "The Ability to Taste: The Eating Body between Laboratory and Clinic." In A Companion to the Anthropology of the Body and Embodiment, edited by Frances Maschia-Lees, 467-480. WileyBlackwell.

- 2012. "Mind Your Plate! The Ontonorms of Dutch Dieting." Social Studies of Science 43: 379-396.

—. Forthcoming. "Language Trails: 'Lekker' and Its Pleasures." To appear in Theory, Culture \& Society.

Mol, Annemarie, Ingunn Moser, and Jeannette Pols, eds. 2010. Care in Practice: On Tinkering in Clinics, Homes and Farms. Bielefeld: Transcript Verlag. 
Pollan, Michael. 2002. The Botany of Desire: A Plant's-Eye View of the World. London: Bloomsbury Publishing.

Pols, Jeanette. 2006. "Accounting and Washing: Good Care in Long-Term Psychiatry.” Science, Technology \& Human Values 31 (4): 409-430.

Rosset, Peter, Robert Rice, and Michael Watts. 1999. "Thailand and the World Tomato: Globalization, New Agricultural Countries (NACs) and the Agrarian Question." International Journal of Sociology of Agricultural and Food 8: 71-85.

Star, Susan Leigh, and James R. Griesemer. 1989. "Institutional Ecology, 'Translations' and Boundary Objects: Amateurs and Professionals in Berkeley's Museum of Vertebrate Zoology, 1907-39." Social Studies of Science 19 (3): 387-420.

Struhkamp, Rita, Annemarie Mol, and Tjalling Swierstra. 2009. "Dealing with Independence: Doctoring in Physical Rehabilitation Practice." Science, Technology \& Human Values 34: 55-76.

Thévenot, Laurent. 2001. "Organizing Complexity: Conventions of Coordination and the Composition of Economic Arrangements." European Journal of Social Theory 4 (4): 405-425.

- 2002. "Which Road to Follow? The Moral Complexity of an 'Equipped' Humanity." In Complexities: Social Studies of Knowledge Practices, edited by John Law and Annemarie Mol, 53-87. Durham/ London: Duke University Press.

Vatin, François. 2013. "Valuation as Evaluation and Valorizing." Valuation Studies 1(1): 31-50.

Watson, James L., and Melissa L. Caldwell. 2005. The Cultural Politics of Food and Eating. Malden, MA: Blackwell Publishing.

Whatmore, Sarah. 2002. Hybrid Geographies: Natures, Cultures, Spaces. London: Sage.

Yates-Doerr, Emily. 2012. "Meeting the Demand for Meat?" Anthropology today 28(1): 11-15. 


\section{Valuation Studies}

Frank Heuts did an MA in Sociology at the University of Amsterdam. He wrote his master's thesis on the question 'what are good tomatoes?'. Currently he is working as a research consultant. In collaboration with colleagues of the Wageningen University and Research Centre he is writing a research proposal to explore the possibilities of increasing people's daily fruit and vegetable consumption. He also has a keen interest in sustainable banking practices.

Annemarie Mol is a professor of Anthropology of the Body at the University of Amsterdam. She has published widely on bodies, science and technology, care practices, topologies and complexities. She is currently working on questions that have to do with eating ('what is it to eat?'); normativities (good/bads, qualifications, appreciating, valuing); and the language of theory (which language; whose language; and what is carried along in which words?) She works with a great team thanks to an Advanced grant of the European Research Committee and a Spinoza Prize of the Netherlands Organization of Scientific Research. 